\title{
Ecosystem attributes of trophic models before and after construction of artificial oyster reefs using Ecopath
}

\author{
Min $\mathrm{Xu}^{1,2,3,6,7}$, Lu $\mathrm{Qi}^{4}{ }^{4}$ Li-bing Zhang ${ }^{1,2,3}$, Tao Zhang ${ }^{1,2,3, *}$, Hong-sheng Yang ${ }^{1,2,3}$, \\ Yun-ling Zhang ${ }^{5}$ \\ ${ }^{1}$ CAS Key Laboratory of Marine Ecology and Environmental Sciences, Institute of Oceanology, \\ Chinese Academy of Sciences, Qingdao 266071, PR China \\ ${ }^{2}$ Laboratory for Marine Ecology and Environmental Science, Qingdao National Laboratory for Marine Science and Technology, \\ Qingdao 266237, PR China \\ ${ }^{3}$ Center for Ocean Mega-Science, Chinese Academy of Sciences, Qingdao 266071, PR China \\ ${ }^{4}$ Ocean University of China, Qingdao 266100, PR China \\ ${ }^{5}$ Hebei Provincial Research Institute for Engineering Technology of Coastal Ecology Rehabilitation, Tangshan 063610, PR China \\ ${ }^{6}$ Present address: Key Laboratory of East China Sea and Oceanic Fishery Resources Exploitation, Ministry of Agriculture, \\ Shanghai 200090, PR China
}

${ }^{7}$ Present address: East China Sea Fisheries Research Institute, Chinese Academy of Fishery Sciences, Shanghai 200090, PR China

ABSTRACT: The deployment of artificial reefs (ARs) is currently an essential component of sea ranching practices in China due to extensive financial support from the government and private organizations. Blue Ocean Ltd. created a $30.65 \mathrm{~km}^{2}$ AR area covered by oysters in the eastern part of Laizhou Bay, Bohai Sea. It is important for the government and investors to understand and assess the current status of the AR ecosystem compared to the system status before AR deployment. We provide that assessment, including trophic interactions, energy flows, keystone species, ecosystem properties and fishing impacts, through a steady-state trophic flow model (Ecopath with Ecosim). The model estimated values of 4721.2 and $4697.276 \mathrm{t} \mathrm{km}^{-2} \mathrm{yr}^{-1}$ for total system throughput and 534.74 and $-519.9 \mathrm{t} \mathrm{km}^{-2} \mathrm{yr}^{-1}$ for net system production before and after AR deployment, respectively. After AR deployment, sea cucumber and oyster showed the same trophic level $(\mathrm{TL}=2.0)$ while veined whelk Rapana venosa had $\mathrm{TL}=3.0$. The mean TL of catches was 2.484 after AR deployment and the primary production required to support fisheries (PPR) was $1104 \mathrm{t} \mathrm{km}^{-2}$. Detritus production dominated over primary production and represented $73.82 \%\left(2530.82 \mathrm{t} \mathrm{km}^{-2}\right)$ of total primary production required. The sea cucumber showed the lowest PPR/catch value (5.6) among functional groups, indicating that fishing catch biomasses were close to primary production values. The total primary production to total respiration and total primary production to total biomass ratios showed higher system maturity after AR deployment. The trophic flow diagram showed 1 grazing and 2 detritus food chains. Pelagic and bottom fish and different benthic organisms, including large crustaceans and zoobenthos, were the dominant community before AR deployment. Zoobenthos was the key functional group, followed by large crustaceans and Gobiidae, which were the most important prey for top predators after AR deployment. We draw the following conclusions for the management of this area: (1) AR deployment contributes to the maturity of the improved ecosystem; (2) the artificial oyster system is similar to a natural reef system; (3) the enhancement and release of benthic animals in the AR area benefit the ecosystem; and (4) low TL catches do not cause the system to collapse.

KEY WORDS: Ecopath model - Artificial oyster reef - Apostichopus japonicus - Rapana venosa · Ecosystem properties $\cdot$ Sea ranching 


\section{INTRODUCTION}

Artificial reefs (ARs) are often used in sea ranching, and they are considered an effective fisheries management tool to improve impaired habitats (smallscale ecosystems) (Myoung \& Park 2001, Sayer \& Wilding 2002, Mustafa et al. 2003, Santos et al. 2006). ARs have been built to prevent destructive trawlers from accessing critical shelter, feeding and spawning grounds for commercially important fish species and to improve fisheries by increasing the harvest of sea cucumber, shellfishes and other fishes (Kakimoto et al. 2000, Freitas et al. 2006, Iannibelli \& Musmarra 2008, Serrano et al. 2011).

ARs are human-made underwater structures (Baine 2001). They can influence nutrient cycling and transport (Falcão et al. 2007, Vicente et al. 2008) and sediment biogeochemistry (Alongi et al. 2008), with subsequent changes in community structure and richness of associated organisms (Langlois et al. 2006). Lowry et al. (2011) reported higher fish biomasses in reef areas compared to areas without reefs, with reef areas supporting larger numbers of fish. Although quantitative assessments of artificial ecosystems including ARs have been performed in $\mathrm{Li}$ Island, Rongcheng City, China (Wu et al. 2016) and Zhangzi Island, Dalian City, China (Z. Xu et al. 2016), few studies have compared ecosystem status before and after AR deployment.

Oysters are filter feeders that feed upon suspended particles in the water column. Their water pumping rates are so high that they are considered an important biofilter that helps maintain system functioning (Grizzle et al. 2006). The biogenic structure formed by vertically upright oyster aggregations creates habitat for dense assemblages of mollusks including oysters, polychaetes, crustaceans and other resident invertebrates (Lenihan et al. 2001, Dillon et al. 2015). Juvenile fish and mobile crustaceans also recruit to and utilize oyster reefs as a refuge and foraging grounds (Luckenbach et al. 2005, Rodney \& Paynter 2006). Removal of filter-feeding oysters from estuaries such as in the Chesapeake Bay and Pamlico Sound, USA, resulted in trophic re-structuring that promoted planktonic and microbial organisms over demersal and benthic flora and fauna (Baird et al. 2004).

China's Bohai Sea ecosystem, one of the most intensively exploited areas in the world (Wigan 1998), is heavily degraded due to overfishing, pollution from inland areas and loss of biological habitat. Open-access and unregulated fisheries contribute to this deteriorating tendency and many small-scale fishermen still make a living through illegal fishing and use of destructive fishing gear in this region (Zhang et al. 2012, M. Xu et al. 2016, 2018a). In 2011, Blue Ocean Ltd. created a $30.65 \mathrm{~km}^{2}$ AR area in the eastern part of Laizhou Bay in the Bohai Sea (see Fig. 1). The company re-organized the scattered smallscale fishermen into coordinated fishing operations and created fishery industries including stock release of the sea cucumber Apostichopus japonicus and stock enhancement of Rapana venosa. This is called 'Ze-Tan development pattern' in China (Yang 2016).

The marine biota and benthic environments of the area are extremely degraded due to continuous overfishing and bottom trawling fishing, which occurred in the eastern part of Laizhou Bay through 2010, before AR deployment. After AR deployment in 2011, oysters began to gradually colonize AR surfaces, and the abundance of economic species such as Octopus spp., Sebastes schlegelii, Hexagrammos otakii, Charybdis japonica and $R$. venosa began to increase. A. japonicus juveniles have been released into AR areas each year since 2013 and form an important fishery in this region. Feces produced by shellfish cultivations, which have been implemented in Laizhou Bay since the 1980s, provide large amounts of detritus to support sea cucumber growth.

In this paper, we constructed trophic models using the Ecopath approach to compare ecosystem status before (2010) and after (2016) AR deployment, and answer the following questions: (1) Did AR deployment contribute to the maturity of the improved ecosystem? (2) Is the artificial oyster system similar to a natural reef ecosystem? (3) Did the enhancement and release of benthic organisms in the AR area benefit the system? (4) Can low trophic-level catches cause the system to collapse? Trophic interactions, energy flows, keystone species, ecosystem properties and fishing impacts are presented to identify and compare energy and matter flows in non-AR versus AR areas in the study system.

\section{MATERIALS AND METHODS}

\subsection{Study site}

ARs were deployed in 2011 in the eastern part of Laizhou Bay, Bohai Sea, PR China $\left(37^{\circ} 15^{\prime}-37^{\circ} 22^{\prime} \mathrm{N}\right.$, $119^{\circ} 38^{\prime}-119^{\circ} 46^{\prime}$ E) (Fig. 1). Once deployed, the reefs were gradually colonized by pacific oyster Crassostrea gigas. Laizhou Bay is a semi-closed basin receiving the inflow of the Yellow River and is characterized by large areas devoted to shellfish cultivation. 
The AR area is $30.67 \mathrm{~km}^{2}$ and includes an Apostichopus japonicus catchment area of $5.34 \mathrm{~km}^{2}$. The mean depth is $\sim 6 \mathrm{~m}$ in the whole AR area.

\subsection{Mass-balance modeling approach}

The Ecopath approach and modeling software (Ecopath with Ecosim [EwE] version 6.5; www. ecopath.org; Christensen \& Walters 2004) was used in this study to assess system structure and perform ecosystem trophic analysis.

The Ecopath model is based on the following equation:

$$
\mathrm{B}_{i}(\mathrm{P} / \mathrm{B})_{i}=\sum_{j=1}^{n} \mathrm{~B}_{j}(\mathrm{Q} / \mathrm{B})_{j} \mathrm{DC}_{j i}+\mathrm{Y}_{i}+\mathrm{B}_{i}(\mathrm{P} / \mathrm{B})_{i} \times\left(1-\mathrm{EE}_{i}\right)
$$

where $\mathrm{B}_{i}$ and $\mathrm{B}_{j}$ are the biomasses of species (or species group) $i$ and its predator $j_{1}(\mathrm{P} / \mathrm{B})_{i}$ is the production-to-biomass ratio of species $i_{r}(\mathrm{Q} / \mathrm{B})_{j}$ is the consumption per unit biomass of predator $j$ and $\mathrm{DC}_{j i}$ is

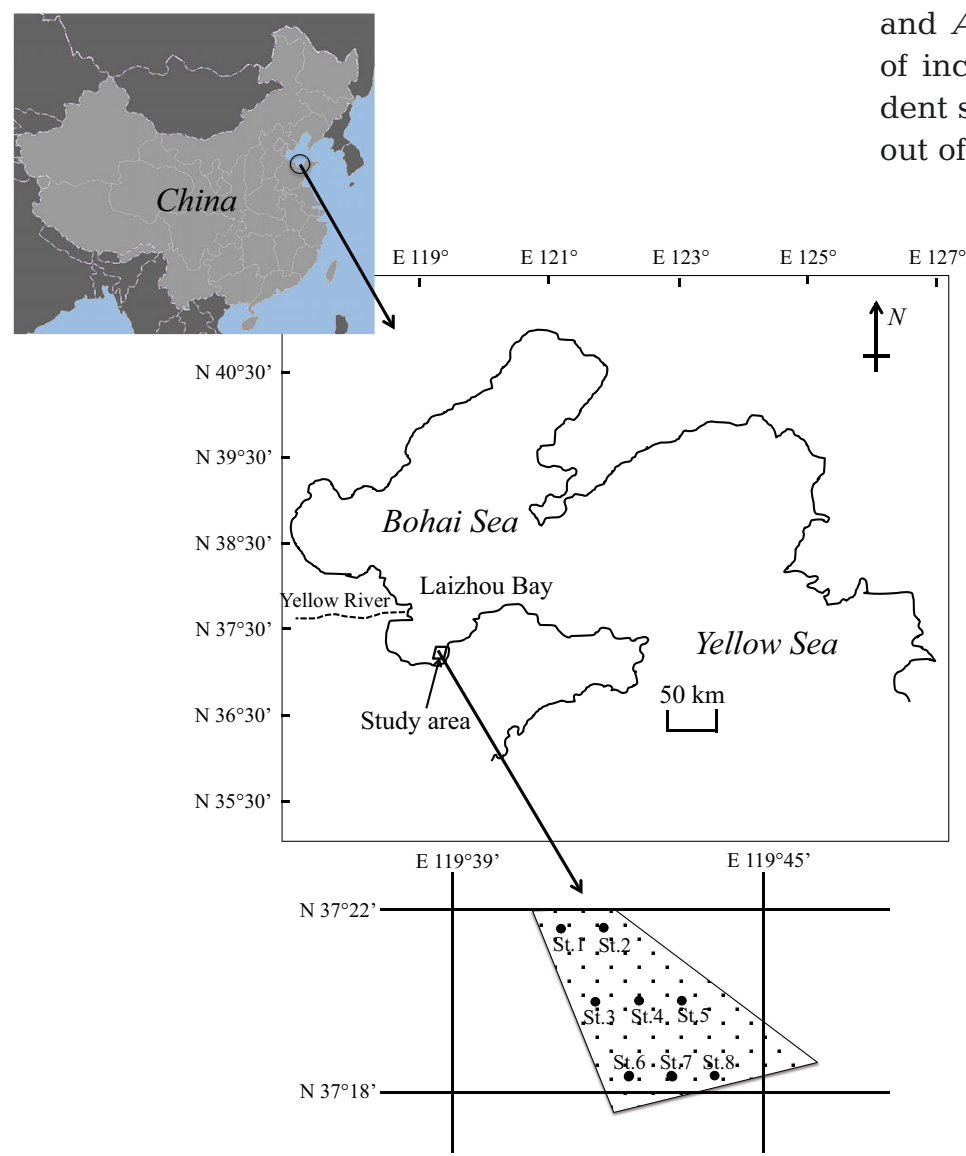

Fig. 1. Model domain in Laizhou Bay, Bohai Sea, PR China. The artificial reef area $\left(\sim 30.65 \mathrm{~km}^{2}\right)$ is denoted by a white trapezoid outlined in black in the nearshore zone of the bay. The Yellow River delta is located in the northwestern region of Laizhou Bay. The survey station is from $\operatorname{Stn} 1$ to $\operatorname{Stn} 8$ the proportion of species $i$ in the diet of predator $j . \mathrm{Y}_{i}$ is the commercial catch for species $i$ and $\mathrm{EE}_{i}$ is the ecotrophic efficiency of species $i$ (the ratio between the biomass flowing out of a group and the biomass flowing in). We built one model representing the system before AR deployment and another model after AR deployment.

\subsection{Sampling and Ecopath input values}

We collected functional group biomass data at 8 sampling stations across the AR area (ca. $30.65 \mathrm{~km}^{2}$ ) (Fig. 1). Samples were collected in 2010 (before AR deployment) and in 2016 (after AR deployment). The main commercial fishing activities in this region include crab pot and diving fishing. Species fished via the crab pot method include benthic organisms such as members of Octopodidae and Gobiidae, Sebastes schlegelii and Charybdis japonica. Species fished via the diving method include Rapana venosa and $A$. japonicus, which represent the main source of income for local fishing communities. Most resident species are important because they feed in and ut of the AR area and can therefore be regarded as immigration items when assessing diet composition. We used crab pots and trawl nets to collect functional group biomass data expressed as $\mathrm{t} \mathrm{km}^{-2}$. We used crab pots to quantify the biomass of $C$. japonica and trawl nets to estimate the biomass of several functional groups including large crustaceans, benthos, demersal fishes and Octopodidae. We connected five $8 \mathrm{~m}$ long crab pots at each survey station so that the total length of our crab pots was $40 \mathrm{~m}$. A trawling survey was carried out at a speed of 2 knots using a trawl net with inner mesh size of $3.5 \mathrm{~cm}$ and mouth width of $2.5 \mathrm{~m}$.

Phytoplankton biomass in terms of chlorophyll a (chl a) was measured using a Turner fluorometer according to standard procedures (Sandu et al. 2003). Zooplankton samples were collected across the water column by means of opening-closing bongo nets with a diameter of $37 \mathrm{~cm}$ and a mesh size of $0.03 \mathrm{~mm}$. Zooplankton biomass was estimated by displaced volume according to Wiebe (1988). Oysters, $R$. venosa and A. japonicus were collected by SCUBA divers scraping them off 0.5 $\times 0.5 \mathrm{~m}^{2}$ quadrats. Sampled organisms were counted and weighed to the nearest $0.1 \mathrm{~g}$ (Xu \& Komatsu 2016, Xu et al. 2018b). Other func- 
tional groups were sampled through crab fishing and trawling. Fish and crustaceans were identified to the lowest possible taxonomic level, counted and weighed to the nearest $0.1 \mathrm{~g}$ wet weight.

The system was partitioned into functional groups based on preferred physical habitat, similar diet and other ecological similarities, such as inhabited water layer, taxonomic proximity and ecological role. Marine organisms were divided into 13 and 17 functional groups before and after AR deployment, respectively (Table 1). Functional groups spanned the main trophic components of the system and included target organisms of all the fishing activities operating in the area. Oysters were assigned a separate group due to their ecological function and large biomass. Octopodidae were separated from other cephalopods for their large biomass and economic value. Detritus was assigned a single group and used to accumulate biomass flows deriving from unassimilated food and dead organic matter.

Values of $\mathrm{B}, \mathrm{P} / \mathrm{B}, \mathrm{Q} / \mathrm{B}, \mathrm{EE}$ and landings were determined for all functional groups using literature and empirical regressions (Supplement 1 at www. int-res.com/articles/suppl/q011p111_supp.pdf [for all supplements] and see Table 2). Input parameter val- ues of each group were set equal to the averages of the parameter values for that group, weighted by the relative biomass of each group. Diet composition of each functional group was determined using diet data obtained from the literature (Supplement 2 and see Table 3). Diets were adjusted to obtain a balanced model. Flows were expressed in $\mathrm{t}$ wet weight $\mathrm{km}^{-2}$ $\mathrm{yr}^{-1}$ and biomasses in $\mathrm{t}$ wet weight $\mathrm{km}^{-2}$. During the balancing process, Ecopath estimated missing parameter values based on mass balance to obtain $E E$ values less than 1.0 for all groups. The years before and after AR deployment (hereafter referred to as $S_{\mathrm{B}}$ and $S_{\mathrm{AR}+\mathrm{Re}}$ ) were set to 2010 and 2016, respectively.

\subsection{Ecosystem attributes}

The attributes used in the Ecopath model are defined as follows:

- Ecosystem maturity is defined in this study as the culmination of an ecosystem's development into a stable state with maximum biomass and/or information content and is quantified using several of Odum's attributes for ecosystem maturity (Odum 1969, Christensen 1995)

Table 1. Functional groups included in the trophic model before (B) and after (A) artificial reef deployment in Laizhou Bay, Bohai Sea, PR China in 2010 and 2016. DOC: dissolved organic carbon; POC: particulate organic carbon

\begin{tabular}{|c|c|}
\hline Group name & Group description \\
\hline 1. Octopodidae $(\mathrm{B}, \mathrm{A})$ & Octopus variabilis, Octopus ocellatus \\
\hline 2. Mesopelagic fishes $(\mathrm{B}, \mathrm{A})$ & $\begin{array}{l}\text { Thryssa kammalensis, Scomberomorus niphonius, Konosirus punctatus, Sardinella } \\
\text { zunasi, Sillago sihama, Setipinna tenuifilis, Argyrosomus argentatus, Johnius } \\
\text { belangerii, Pampus argenteus, Eupleurogrammus muticus, Takifugu pseudommus }\end{array}$ \\
\hline 3. Demersal fish $(\mathrm{B}, \mathrm{A})$ & $\begin{array}{l}\text { Liza haematocheila, Platycephalus indicus, Saurida elongate, Kareius bicoloratus, } \\
\text { Cynoglossus joyneri, Callionymus kitaharae, Paralichthys olivaceus, Enerias fangi, } \\
\text { Cottiusculus gonez, Sparus macrocephalus, Hippocampus fasciatus }\end{array}$ \\
\hline 4. Sebastes schlegeli $(\mathrm{B}, \mathrm{A})$ & Single species \\
\hline 5. Hexagrammos otakii (A) & Single species \\
\hline 6. Gobiidae $(\mathrm{B}, \mathrm{A})$ & $\begin{array}{l}\text { Acanthogobius ommaturus, Chaeturichthys stigmatias, Ctenotrypauchen chinensis, } \\
\text { Tridentiger trigonocephalus }\end{array}$ \\
\hline 7. Charybdis japonica $(\mathrm{B}, \mathrm{A})$ & Single species \\
\hline 8. Oratosquilla oratoria $(\mathrm{B}, \mathrm{A})$ & Single species \\
\hline 9. Large crustacean $(\mathrm{B}, \mathrm{A})$ & $\begin{array}{l}\text { Palaemon gravieri, Fenneropenaeus chinensis, Lysmata vittata, Trachypenaeus } \\
\text { curvirostris, Palaemon (Exopalamon) carincauda Holthuis, Alpheus japonicas, } \\
\text { Portuns trituberculatus, Philyra carinata, Dorippe japonica, Eucrate crenata, } \\
\text { Matuta planipes, porcelain crab, Dorippe polita }\end{array}$ \\
\hline 10. Other cephalopods (B,A) & Loligo chinensis \\
\hline 11. Rapana venosa (A) & Single species \\
\hline 12. Apostichopus japonicas (A) & Single species \\
\hline 13. Zoobenthos $(\mathrm{B}, \mathrm{A})$ & Gastropods, bivalves, polychaetes, echinoderms, crustaceans \\
\hline 14. Oyster (A) & Ostrea plicatula, Crassostrea gigas \\
\hline 15. Zooplankton $(\mathrm{B}, \mathrm{A})$ & Larva, Copepoda, jellyfish, Cladocera, Chaetognatha, Tunicata, Phylum \\
\hline 16. Phytoplankton $(\mathrm{B}, \mathrm{A})$ & Coscinodiscus spp., Chaetoceros spp., Navicula spp. \\
\hline 17. Detritus $(\mathrm{B}, \mathrm{A})$ & DOC, suspension POC, detritus from shellfish cultivations \\
\hline
\end{tabular}


- In Ecopath, trophic levels (TL; dimensionless) are fractional (e.g. 1.3, 2.7, etc.), as suggested by Odum \& Heald (1975). A routine assigns a TL value of 1 to primary producers and detritus and a TL value of 1 plus the weighted average of the prey's TLs to consumers

- The Finn cycling index is the fraction of an ecosystem's throughput that is recycled and it is strongly correlated with system maturity, resilience and stability

- The system omnivory index (SOI) is defined as the average omnivory index of all consumers weighted by the logarithm of each consumer's food intake. The SOI is a measure of how the feeding interactions are distributed across trophic levels

- $\mathrm{PPr} / \mathrm{R}$ is the ratio between total primary production (PPr) and total respiration (R) in a system. In mature systems, the ratio should approach 1, i.e. the energy that is fixed is approximately balanced by the cost of maintenance

- The ratio between a system's PPr and its total biomass, indicated as PPr/B, is expected to be a function of the system's maturity. In immature systems, production exceeds respiration for most groups, and as a consequence, one can expect the biomass to accumulate over time

- The total system throughput (TST) is the sum of all flows in a system and is expressed in $\mathrm{t} \mathrm{km}^{-2} \mathrm{yr}^{-1}$. TST represents the 'size of the entire system in terms of flow' (Ulanowicz 1986)

- The total biomass (TB) that is supported by the available energy flow in a system (TB/TST) is expected to increase to a maximum for the most mature stages of a system (Odum 1971)

- Based on the options selected for each parameter in each group, a pedigree index can be calculated as the product of all the parameter-specific pedigree indices

- Based on trophic aggregation tables, transfer efficiencies between successive discrete trophic levels can be calculated as the ratio between the sum of the exports from a given TL, plus the flow that is transferred from one TL to the next, and the throughput on the TL. This information is presented in a table with transfer efficiencies (\%) by TL

- The connectance index (CI) of a food web is the ratio of the number of actual links to the number of possible links. Odum (1971) expected food chain structure to change from linear to web-like as systems mature. Hence, the CI can be expected to be correlated with maturity

- The mixed trophic impact (MTI) for living groups is calculated by constructing an $n \times n$ matrix, where the $i_{1} j^{\text {th }}$ element representing the interaction between the impacting group $i$ and the impacted group $j$ is $\mathrm{MTI}_{i, j}=\mathrm{DC}_{i, j}-\mathrm{FC}_{j, i}$, where $\mathrm{DC}_{i, j}$ is the diet composition term expressing how much $j$ contributes to the diet of $i$, and $\mathrm{FC}_{j, i}$ is a host composition term giving the proportion of the predation on $j$ that is due to $i$ as a predator. The matrix is inversed using a standard matrix inversion routine

- Keystones are defined as relatively low-biomass species with a structuring role in their food webs. The analysis of the MTIs presented here was applied to a suite of mass-balance models, and the results allow us to rank functional groups by their keystoneness

- Net food conversion efficiency (NE) is calculated as the ratio between production and the portion of food that is assimilated, i.e. $\mathrm{NE}=\mathrm{P} /(\mathrm{P}+\mathrm{R})$

- Gross food conversion efficiency (GE) is the ratio between production and consumption (P/Q)

- The ratio $\mathrm{P} /(\mathrm{P}+\mathrm{R})$ cannot exceed 1 , because respiration cannot exceed assimilation. For top predators, whose production is relatively low, the $\mathrm{P} /(\mathrm{P}+$ $\mathrm{R})$ ratio can be expected to be close to 1

- The P/R ratio expresses the fate of the assimilated food. Computationally, this ratio can take any positive value, though thermodynamic constraints limit the realized range of this ratio to values lower than 1

- The R/B ratio can be seen as an expression of the activity of a group. The higher the activity level is for a given group, the higher the ratio. The $\mathrm{R} / \mathrm{B}$ ratio is strongly impacted by the assumed fraction of the food that is not assimilated

\subsection{Model calibration and validation}

We followed best practices in Ecopath modeling (Heymans et al. 2016) using the following steps: before the first run, we changed the excretion/egestion rate for zooplankton, sea cucumber and oyster from $20 \%$ (Ecopath default value) to $40 \%$ because it is more realistic from a physiological point of view; we balanced the model to achieve EE values lower than 1.0; and we checked that the following criteria were met: (1) GE values varied between 0.1 and 0.3 ; (2) the estimated NE values of all functional groups were greater than the GE values; (3) $\mathrm{P} /(\mathrm{P}+\mathrm{R})$ ratios were lower than 1.0 ; (4) $\mathrm{P} / \mathrm{R}$ ratios were lower than 1.0 ; and (5) R/B ratios varied between 1 and 10 for fish compartments and between 50 to 100 for groups with higher turnover rates (higher P/B and Q/B values).

We also used the pre-balanced (PREBAL) diagnosis (Link 2010) to identify issues in the model structure 
and in data quality before balancing the network model. Specifically, we checked the following: (1) biomass across taxa and trophic levels; (2) biomass ratio; (3) vital rates across taxa and trophic levels; (4) vital rate ratios; and (5) total production and removals (Link 2010) (Supplement 3). For example, we analyzed the main relationships among $\mathrm{B}, \mathrm{P}, \mathrm{Q}$ and TL. Biomass should span 5-7 orders of magnitude and $\mathrm{P} / \mathrm{B}$ and $\mathrm{Q} / \mathrm{B}$ should decrease when TL increases. We also checked vital rates ratios. For example, rates of predators must be lower than prey's rates and R/P rates must be lower than 1 (Link 2010).

To evaluate the quality of input data, we estimated the pedigree index for each input parameter value $(B$, $\mathrm{P} / \mathrm{B}, \mathrm{Q} / \mathrm{B}$ and the diet matrix elements), attributing values between 0 (low quality) and 1 (high quality) according to the source of information. The average values for all parameters and groups provided a general concise index of the model input data quality.

\section{RESULTS}

\subsection{Evaluation of compartment parameter estimates}

Table 2 summarizes the input values used in the initial and final model runs and the output parameter values estimated by the model (TL and EE). The diet matrix was modified during the balancing procedure (Table 3). The pedigree index was $0.743-0.826$, suggesting that the data used in the model were of very high quality.

Most functional groups, including Sebastes schlegelii, Charybdis japonica, large crustaceans, zoobenthos and zooplankton, had the same TLs in $S_{\mathrm{B}}$ and $S_{\mathrm{AR}+\mathrm{Re}}$. Sea cucumber and oyster had a TL of 2.0, while Rapana venosa had a TL of 3.0 in $S_{\mathrm{AR}+\mathrm{Re}}$ (Table 2).

After AR deployment, detritus showed a high EE $(\mathrm{EE}=0.993)$, implying that biomass accumulation was almost equal to consumption. The comparatively high EE of phytoplankton (EE $=0.950-0.955)$ indicates that a major portion of phytoplankton production was consumed by grazing and the rest settled as detritus (Table 2).

\subsection{Summary of ecosystem attributes}

The model estimated TST values of 4721.2 and $4697.276 \mathrm{t} \mathrm{km}^{-2} \mathrm{yr}^{-1}$ in $S_{\mathrm{B}}$ and $S_{\mathrm{AR}+\mathrm{Re}}$, respectively. Of those values, 37.8 and $47.1 \%$ was due to consumption (1784.55 and $2212.1 \mathrm{t} \mathrm{km}^{-2} \mathrm{yr}^{-1}$ ), 15.64 and $22.91 \%$ to respiratory processes (738.58 and $1076.1 \mathrm{t} \mathrm{km}^{-2} \mathrm{yr}^{-1}$ ),
26.03 and $28.45 \%$ was associated with flows back to detritus (1229.1 and $1336.593 \mathrm{t} \mathrm{km}^{-2} \mathrm{yr}^{-1}$ ), and 20.52 and $1.54 \%$ was due to export processes (969.0 and $72.486 \mathrm{t} \mathrm{km}^{-2} \mathrm{yr}^{-1}$ ) (Table 4). The model estimated values of 1659.1 and $944.439 \mathrm{t} \mathrm{km}^{-2} \mathrm{yr}^{-1}$ for the sum of all production, 1273.32 and $556.2 \mathrm{t} \mathrm{km}^{-2} \mathrm{yr}^{-1}$ for total net primary production and 534.74 and $-519.9 \mathrm{t} \mathrm{km}^{-2} \mathrm{yr}^{-1}$ for net system production in $S_{\mathrm{B}}$ and $S_{\mathrm{AR}+\mathrm{Re}}$ respectively (Table 4 ). The sum of flow to detritus was 795.3 in $S_{\mathrm{B}}$ and $927.6 \mathrm{t} \mathrm{km}^{-2}$ in $S_{\mathrm{AR}+\mathrm{Re}}$ (Table 5).

In both $S_{\mathrm{B}}$ and $S_{\mathrm{AR}+\mathrm{Re}}$, TL III had the highest transfer efficiency, while TL II showed the highest sum of flow to detritus, followed by TL I (Table 5). The total primary production to total respiration (TPP/TR), total primary production to total biomass (TPP/TB) and total biomass to total throughput (TB/TST) ratios showed that system maturity was higher in $S_{\mathrm{AR}+\mathrm{Re}}$ than in $S_{\mathrm{B}}$ (Table 4). Finn's cycling index and Finn's mean path length showed that more groups were cycled into energy flows in $S_{\mathrm{AR}+\mathrm{Re}}$.

Modeled flows and biomasses were represented by means of flow diagrams, which included 1 grazing and 2 detritus food chains after AR deployment (Fig. 2). The grazing food chain was based on a planktonic trophic pathway connecting large crustaceans, C. japonica, Gobiidae and Octopodidae, the latter being at the top of the food web. Two additional food chains were based on detritus and were dominated by sea cucumber and $R$. venosa, the latter connected to detritus by oyster. Oyster and sea cucumber played a prominent role in the overall flow to detritus (414.84 and $258.79 \mathrm{t} \mathrm{km}^{-2}$, respectively) (Table 2). The net efficiencies of sea cucumber ( $\mathrm{NE}=$ $0.298), R$. venosa $(\mathrm{NE}=0.355)$ and oyster $(\mathrm{NE}=0.188)$ were the highest in $S_{\mathrm{AR}+\mathrm{Re}}$ (Table 2).

\subsection{MTI and keystone species analyses}

Results of the MTI and keystone species analyses are shown in Fig. 3 and Table 6. All functional groups except for detritus had a negative impact on themselves, indicating resource competition within groups (Christensen et al. 2005). Detritus had neither positive nor negative impacts on itself, possibly because it is not a living organism. Cephalopods other than Octopodidae and Oratosquilla oratoria showed weak impacts on other groups, either because of their very small populations or lack of diet data.

Model results exhibited several similar positive and negative impacts on each compartment in $S_{\mathrm{B}}$ and $S_{\mathrm{AR}+\mathrm{Re}}$, with the impact magnitudes showing substantial variability (Fig. 3). Octopodidae had a posi- 


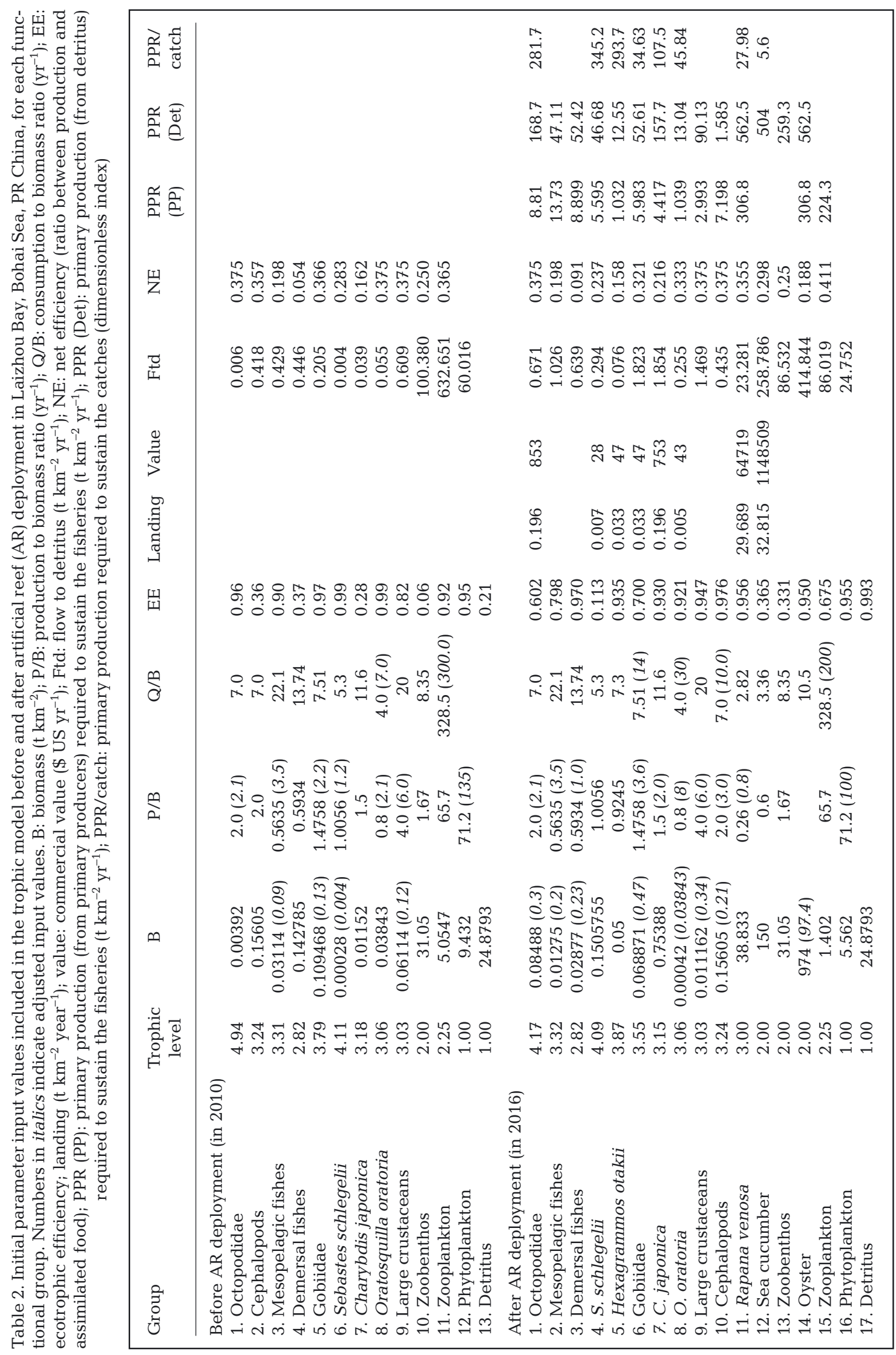




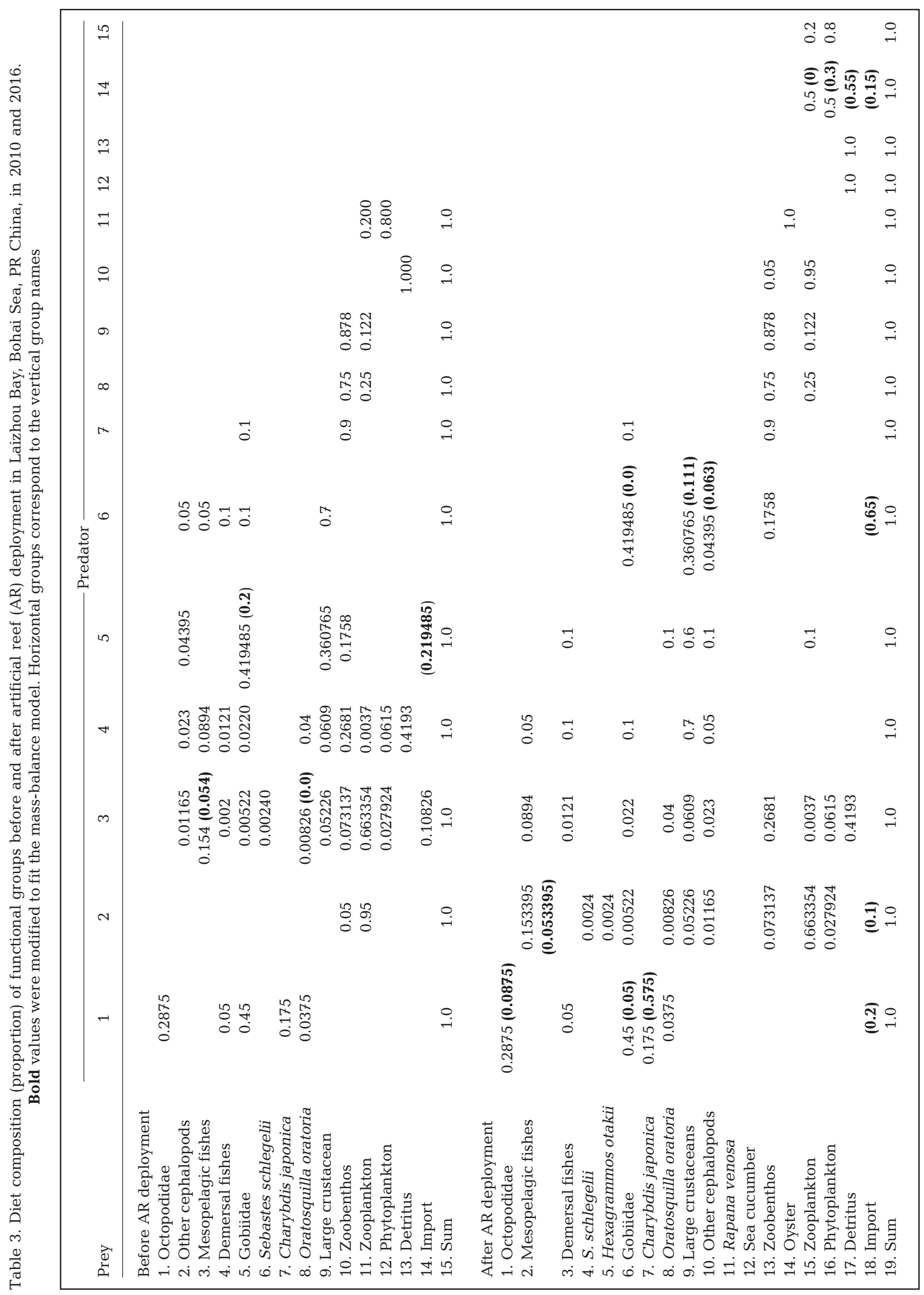




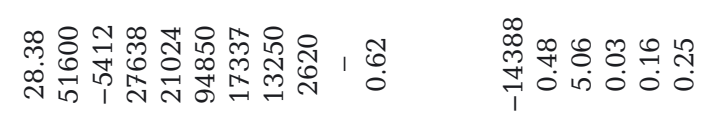

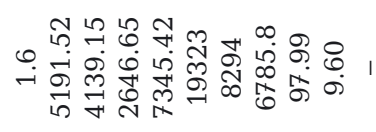

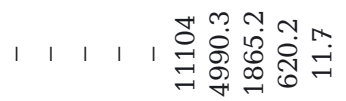

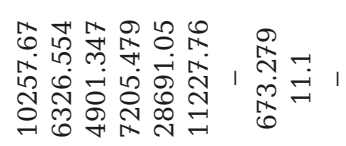

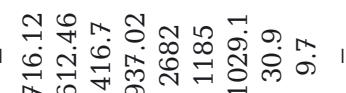

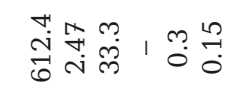

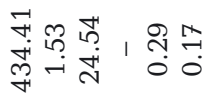

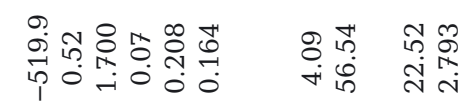

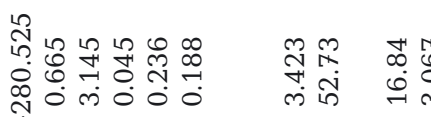

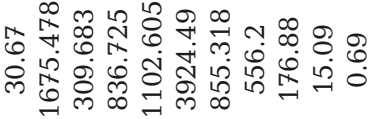

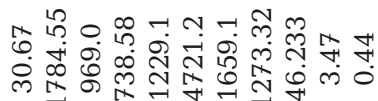

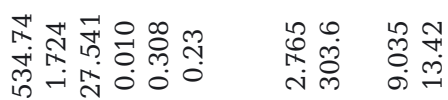

疍

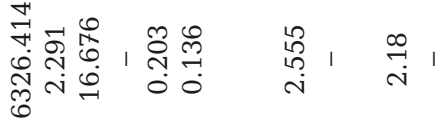

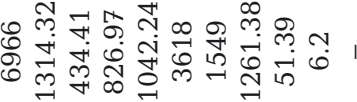

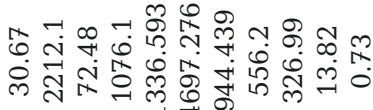

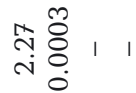

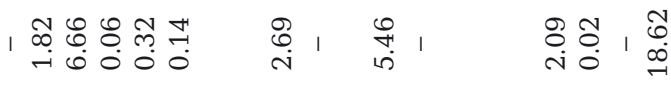
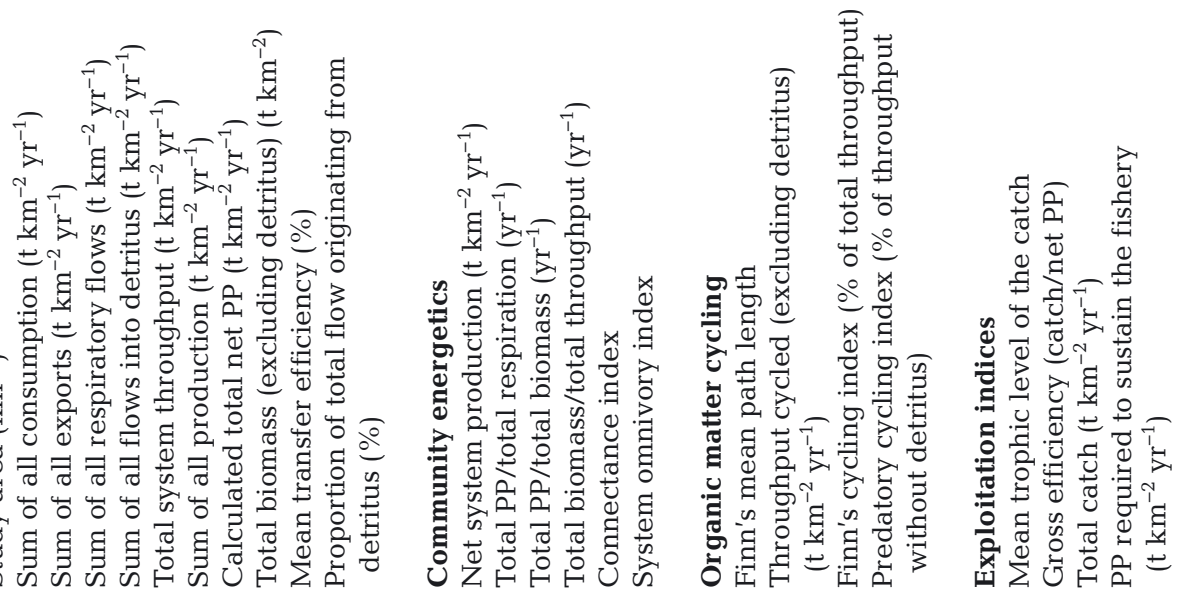

बूँ

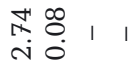

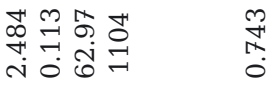

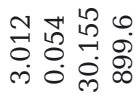

8
0
0
0

$\underset{\substack{0 \\ \infty \\ 0 \\ 0}}{0}$

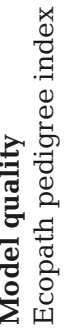


Table 5. Transfer efficiency at trophic levels I to V before and after artificial reef deployment showing the contribution of detritus and primary production to the trophic network in Laizhou Bay, Bohai Sea, PR China, in 2010 and 2016

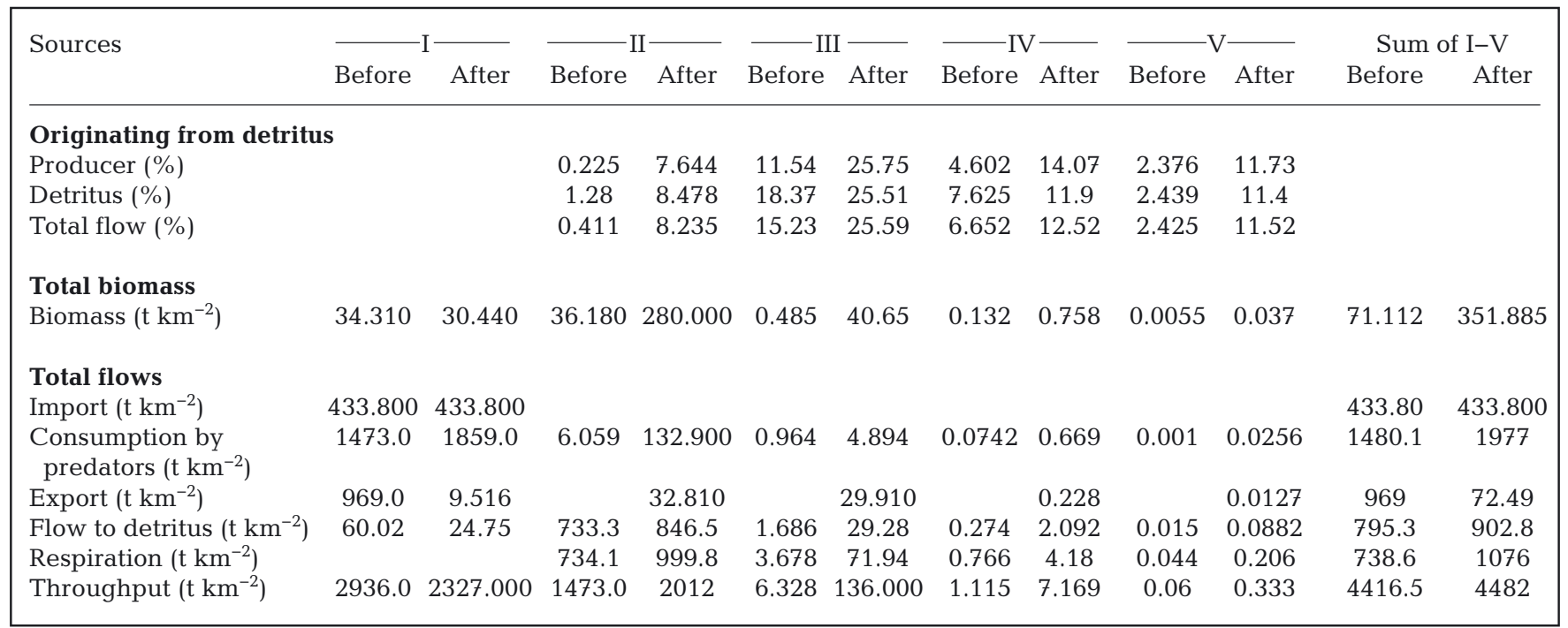

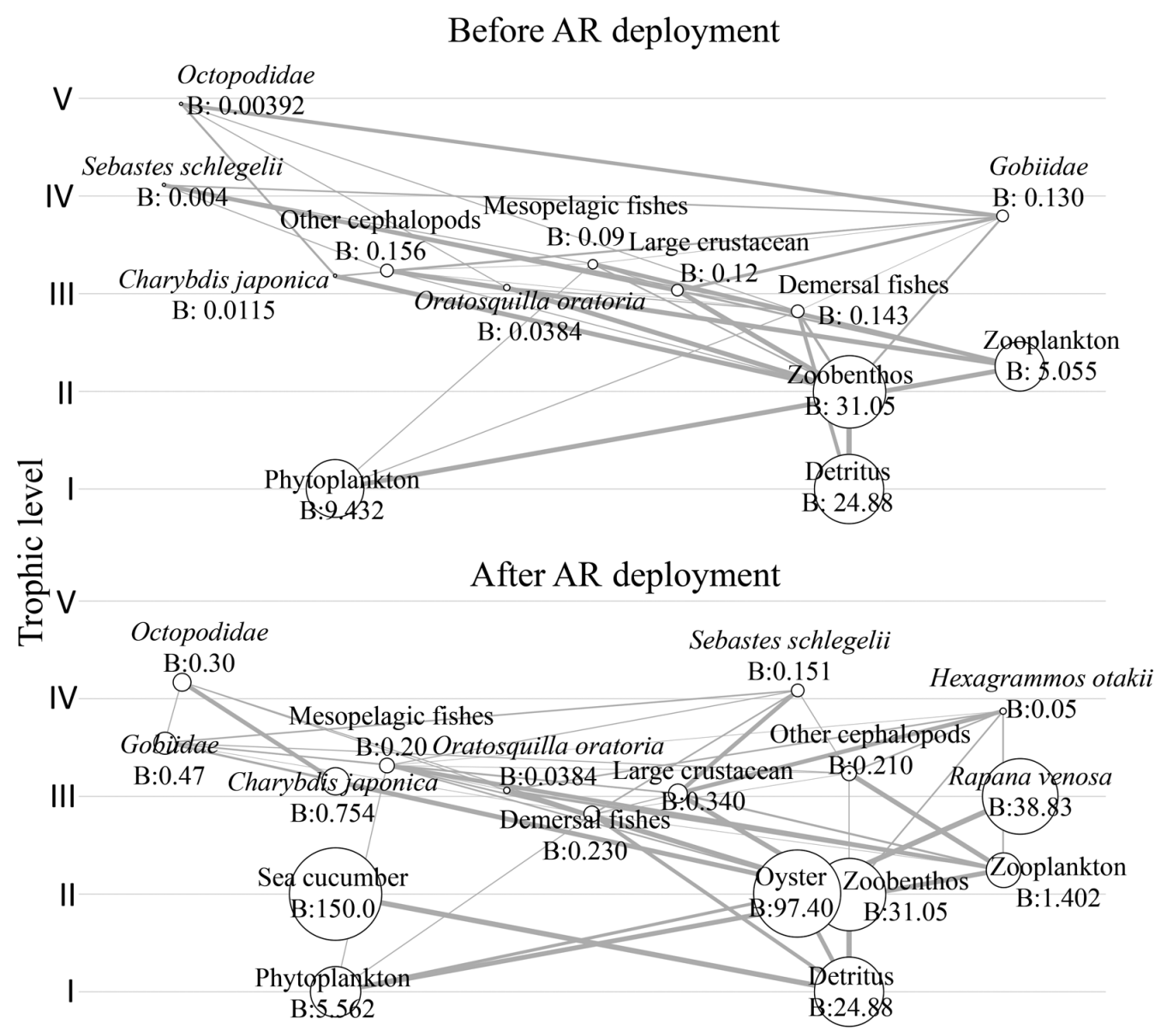

Fig. 2. Flow diagrams representing food web structure (Ecopath with Ecosim modeling) in terms of functional groups and fractional trophic levels before and after artificial reef (AR) deployment. Circles are distributed on the $y$-axis according to trophic level (I-V); circle size is proportional to each group's biomass. Biomass (B) is reported in $\mathrm{t} \mathrm{km}^{-2}$. Line thickness illustrates the magnitude of the flow rates 


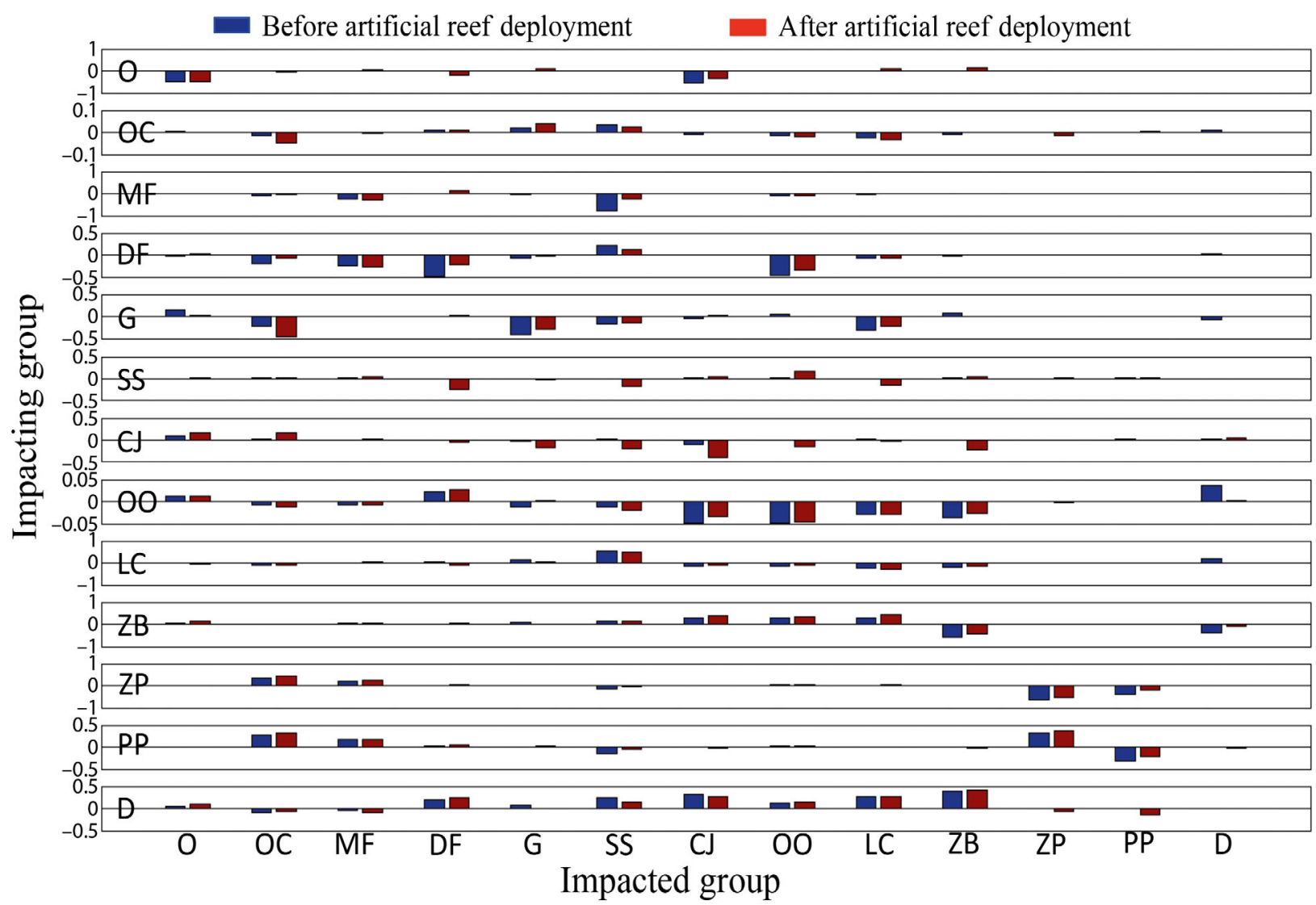

Fig. 3. Comparison of mixed trophic impact analysis results before and after artificial reef deployment. Impacting and impacted groups are placed along the vertical and horizontal axis, respectively. Positive impacts are shown above the baseline; negative impacts are below the baseline. The impacts are relative but comparable between groups. O: Octopodidae; OC: other cephalopods; MF: mesopelagic fishes; DF: demersal fishes; G: Gobiidae; SS: Sebastes schlegelii; CJ: Charybdis japonica; OO: Oratosquilla oratoria; LC: large crustaceans; ZB: zoobenthos; ZP: zooplankton; PP: phytoplankton; D: detritus

tive impact on the biomass of Gobiidae, large crustaceans and zoobenthos, and a negative impact on the biomass of $S$. schlegelii. An increase in the production of C. japonica resulted in higher Octopodidae biomass but lower Gobiidae and zoobenthos biomasses. S. schlegelii had a positive impact on $C$. japonica and zoobenthos biomass and a negative impact on Gobiidae and large crustaceans.

The biomass of Octopodidae was positively affected by increases in the production of C. japonica, zoobenthos and detritus, while the biomass of $S$. schlegelii was negatively affected by decreases in the production of Octopodidae and $O$. oratoria. The biomass of $C$. japonica was positively (or negatively) associated with increases (or decreases) in the production of $S$. schlegelii and zoobenthos (or demersal fishes, C. japonica and phytoplankton). The biomass of Gobiidae increased (or decreased) due to an increase (or decrease) in the production of Octopodidae, other cephalopods, zooplankton and phytoplankton (or S. schlegelii and C. japonica).
According to the keystone species analysis, pelagic and bottom fish groups and different benthic organisms, including large crustaceans and zoobenthos, were the dominant community in $S_{\mathrm{B}}$ (Table 6). Zoobenthos was the key group in $S_{\mathrm{AR}+\mathrm{Re}}$, followed by Gobiidae and large crustaceans, which are the most important prey compartments for top predators in the system. Plankton and oyster ranked $5^{\text {th }}$ to $7^{\text {th }}$, exhibiting large populations and negative impacts on each other. O. oratoria and cephalopods other than Octopodidae ranked $15^{\text {th }}$ to $16^{\text {th }}$ due to their small population biomass (Table 6).

\subsection{Fishing status}

The primary production required to support fisheries (PPR, considering primary production and detritus) was $3428.42 \mathrm{t} \mathrm{km}^{-2}$ (Table 2). $R$. venosa represented $34.18 \%\left(306.8 \mathrm{t} \mathrm{km}^{-2}\right)$ of the PPR fraction coming from primary production and $22.23 \%(562.5 \mathrm{t}$ 
Table 6. Keystone index \#3 against relative total impact of each functional group before and after artificial reef deployments in Laizhou Bay, Bohai Sea, PR China, in 2010 and 2016

\begin{tabular}{|c|c|c|c|c|c|}
\hline \multirow[t]{2}{*}{ Group name } & \multicolumn{2}{|c|}{ Before } & \multirow[t]{2}{*}{ Group name } & \multicolumn{2}{|c|}{$\longrightarrow$ After } \\
\hline & $\begin{array}{l}\text { Relative total } \\
\text { impact }\end{array}$ & $\begin{array}{l}\text { Keystone } \\
\text { index \#3 }\end{array}$ & & $\begin{array}{l}\text { Relative total } \\
\text { impact }\end{array}$ & $\begin{array}{l}\text { Keystone } \\
\text { index \#3 }\end{array}$ \\
\hline 1. Mesopelagic fishes & 1 & 0.803 & 1. Zoobenthos & 1 & 0.506 \\
\hline 2. Demersal fishes & 0.857 & 0.532 & 2. Gobiidae & 0.876 & 0.749 \\
\hline 3. Large crustaceans & 0.794 & 0.645 & 3. C. japonica & 0.853 & 0.68 \\
\hline 4. Zooplankton & 0.717 & 0.233 & 4. Large crustaceans & 0.805 & 0.764 \\
\hline 5. Zoobenthos & 0.707 & -0.251 & 5. Oyster & 0.668 & 0.0292 \\
\hline 6. Octopodidae & 0.66 & 0.799 & 6. Phytoplankton & 0.666 & 0.426 \\
\hline 7. Phytoplankton & 0.565 & -0.0467 & 7. Zooplankton & 0.657 & 0.499 \\
\hline 8. Gobiidae & 0.541 & 0.412 & 8. Octopodidae & 0.626 & 0.7 \\
\hline 9. Charybdis japonica & 0.116 & -0.0349 & 9. Demersal fishes & 0.582 & 0.71 \\
\hline 10. Sebastes schlegelii & 0.0765 & -0.175 & 10. Mesopelagic fishes & 0.569 & 0.772 \\
\hline 11. Oratosquilla oratoria & 0.0732 & -0.281 & 11. Rapana venosa & 0.533 & 0.108 \\
\hline \multirow[t]{5}{*}{ 12. Other cephalopods } & 0.0644 & -0.689 & 12. S. schlegelii & 0.441 & 0.694 \\
\hline & & & 13. Sea cucumber & 0.37 & -0.529 \\
\hline & & & 14. Hexagrammos otakii & 0.192 & 0.364 \\
\hline & & & 15. Other cephalopods & 0.12 & 0.0611 \\
\hline & & & 16. O. oratoria & 0.118 & 0.178 \\
\hline
\end{tabular}

$\mathrm{km}^{-2}$ ) of the PPR fraction coming from detritus production (Table 2). The sea cucumber exhibited $19.91 \%\left(504 \mathrm{t} \mathrm{km}^{-2}\right)$ of the PPR coming from detritus (Table 2). Detritus production (2530.825 t km-2) represented the largest portion $(73.82 \%)$ of overall PPR (Table 2). The sea cucumber showed the lowest PPR/catch value (5.6) among functional groups, indicating fishing catch biomass values close to primary production values (Table 2 ).

\section{DISCUSSION}

\subsection{AR deployment contributed to the maturity of the improved ecosystem}

Ecosystem maturity improved through AR deployment, as verified by the ratios TPP/TR, TPP/TB and TB/TST. Ecosystem development is seen by Odum (1969) as a process that involves structural changes in the system that are orderly and directional. Ecosystem development is to culminate in a stable system with maximum biomass and/or information content, a state referred to as ecosystem maturity (Christensen 1995). Guan et al. (2016) showed that a restoration project aimed at enhancing biological habitat and improving biotic environment using ARs (Pitcher et al. 2002), hard slope roughing (Moschella et al. 2005) and stock releasing (Borsje et al. 2011) resulted in increased ecosystem maturity in the harbor of the Tianjin Lin Gang Economic Zone, PR China. Similarly, in Hangzhou Bay, China, Xu et al.
(2011) found that an artificial coastal ecosystem enhanced system maturity.

ARs have become an important technique to restore degraded habitats and marine resources worldwide (Rilov \& Benayahu 2000, Woo et al. 2014), including China. AR ecosystems enhance secondary biomass production through increased survival and growth of new individuals as a result of improved sheltering and food resources provided by the reef (Langlois et al. 2006). Uneven surfaces with cracks, crevices and holes typical of ARs also increase benthic diversity and biomass (Moura et al. 2006, Bruce et al. 2012). As evidence of those improvements, transfer efficiencies were 3.47 and $13.82 \%$ in $S_{\mathrm{B}}$ and $S_{\mathrm{AR}+\mathrm{Re}}$, respectively (Table 4 ), the latter being close to the mean value (15\%) proposed by Ryther (1969) for temperate coastal ecosystems.

The CI of $S_{\mathrm{B}}$ was higher than that of $S_{\mathrm{AR}+\mathrm{Re}}$, showing that ARs can shorten and modify the food web and increase net production. Claudet \& Pelletier (2004) and Lowry et al. (2011) reported higher biomasses in reef areas than in areas without reefs, with reef areas supporting large numbers of fish. Pitcher et al. (2002) utilized Ecopath to simulate the marine ecosystem of Hong Kong and investigate the relationship between reef fish biomass and the relative size of ARs inside marine protected areas (AR/MPA). They concluded that total reef fish biomass would increase by $30 \%$ (from 190 to 247 t) in a $2 \%$ AR/ MPA system after $10 \mathrm{yr}$.

In this study, after AR deployment, sedentary organisms such as sea cucumbers and oysters, which 
feed mainly on detritus, were subjected to stock release and enhancement, respectively. Mobile fauna commonly inhabiting AR structures include burrowing species (infauna) and free-living species that shelter in crevices (sedentary species) (Lira et al. 2010). Apostichopus japonicus, whose natural range in Asia covers the coasts of Russia, Japan, China and Korea from 35 to $44^{\circ} \mathrm{N}$ (Yuan et al. 2009), has become an important component of the mariculture sector in northern China (Zhang et al. 2011). Soaring market prices in China were responsible for stimulating the release of A. japonicus in AR areas. Oysters are a major prey for Rapana venosa in the system (Golikov \& Skarlato 1967), while the economic species $A$. japonicus and $R$. venosa have no predators except for fishing in this area. It was also found that the populations of Octopodidae, Sebastes schlegelii, Hexagrammos otakii and Charybdis japonica began to expand and their juveniles were caught in AR areas, suggesting that AR areas acted as an important fish breeding, sheltering and feeding ground in Laizhou Bay. H. otakii and S. schlegelii, which are both common along the coast of northern China (Zhang et al. 2008) and have similar feeding modes and habitat preferences, competed for the prey group represented by large crustaceans, while members of the Gobiidae family were a common prey for S. schlegelii and Octopodidae. Based on stable isotope analyses, $\mathrm{Xu}$ et al. (2017) concluded that $S$. schlegelii was carnivorous in an AR ecosystem in Laizhou Bay, while $H$. otakii had a more complex diet including seaweed debris. In our study, a food chain based on zoobenthos and connected by C. japonica to the top predator Octopodidae was found in the system's food web.

\subsection{The artificial oyster system is similar to a natural reef ecosystem}

The Laizhou AR ecosystem, a representative artificial oyster reef area in the nearshore rocky reef waters of the northern coast of China, was characterized by greater benthic than pelagic productivity. ARs can retain detritus effectively and provide suitable habitat to epifauna and the surrounding natural fauna community (Xu et al. 2017). Several sessile organisms, especially oysters, usually colonize newly deployed reefs very rapidly owing to the complex structure provided to them by reefs. Thus, lower TL consumers such as the detritivorous $A$. japonicus and herbivorous Crassostrea gigas dominated the system, and these organisms were the main sources of biomass flowing to detritus (Table 2), thereby contributing to the high productivity and standing crop of benthic organisms in the area. In rocky reef systems, the planktonic-benthic pathway is regarded as an important pathway for importing large quantities of carbon and trapping it by filter- and suspension-feeding invertebrates (Bray et al. 1981).

The high biomass of oyster $\left(\mathrm{B}=97.4 \mathrm{t} \mathrm{km}^{-2}\right)$, sea cucumber $\left(\mathrm{B}=150 \mathrm{t} \mathrm{km}^{-2}\right)$ and other benthic organisms in the system is likely related to the nutritional support provided by the much higher biomass of detritus. The detritus pool was likely supplemented with biomass accumulations from the surrounding shellfish farms that are widespread in the Laizhou region. In an artificial coastal ecosystem in Hangzhou Bay, detritus contributed $57 \%$ of the total energy flux, indicating that the artificial ecosystem depended more on the detritus pool than on primary producers to generate TST (Xu et al. 2011). At the same time, oysters also exerted high predation pressure upon phytoplankton, as indicated by the decrease in phytoplankton biomass after AR deployment (Table 2).

Natural subtidal rocky reefs in Galápagos, Chile (Okey et al. 2004) and artificial oyster reefs in Laizhou, China share general similarities, as suggested by some of the indexes, including TPP/TR, TPP/TB, TB/TST and the proportion of total flow originating from detritus (Table 4). Both systems have negative net system production. However, food web complexity is higher in the subtidal rocky reefs, as indicated by the system omnivory index (SOI = 0.25). In addition, the values of TST, sum of all production, total net primary production and total biomass excluding detritus are several times higher for the AR ecosystems in Zhangzi Island ( $\mathrm{Z}$. $\mathrm{Xu}$ et al. 2016) and Li Island (Wu et al. 2012) than the values obtained for the AR area in Laizhou Bay, although far lower than the values estimated for rocky reefs in Galápagos. Low TST and total production in Laizhou indicate that this system has relatively lower internal energy compared to other AR ecosystems in China and subtidal rocky reefs. The Laizhou AR area was created only 5 yr before this study, a rather short time, suggesting that the ecosystem is still in an early development stage in terms of production, throughput and biomass.

\subsection{Enhancement and release of benthic organisms in AR areas benefit the ecosystem}

Stock release, which is generally thought to be more effective in AR areas than in non-AR areas, can induce dramatic ecosystem changes (Watson 1993, 
Grosholz et al. 2000). In China, significant efforts have been made to increase fisheries production through large-scale release programs of cultured juveniles, e.g. the penaeid prawn Penaeus chinensis (Wang et al. 2006) and A. japonicus (Chen 2004, Choo 2008, Han et al. 2016).

$A$. japonicus has been released in the Laizhou AR area while the economic species $R$. venosa has been enhanced owing to the availability of sheltering places and large amounts of prey animals such as oysters. We compared this system with other systems that were subjected to stock release, such as the release of Fenneropenaeus chinensis into Laizhou Bay (Lin et al. 2013) and Portunus trituberculatus into the Yellow River estuary and adjacent waters (Lin et al. 2015). The TPP/TR and TPP/TB values of $S_{\mathrm{B}}$ were similar to those of the systems where release of $F$. chinensis and $P$. trituberculatus occurred, showing that these systems have similar maturity. TST and total biomass excluding detritus, which represent the system's internal energy, in $S_{\mathrm{AR}+\mathrm{Re}}$ than in the systems subjected to the release of $F$. chinensis and P. trituberculatus. Furthermore, more trophic compartments were involved in energy flows in $\mathrm{S}_{\mathrm{AR}+\mathrm{Re}}$, according to Finn's cycling index, compared to the other 2 systems. Mean transfer efficiency in $\mathrm{S}_{\mathrm{AR}+\mathrm{Re}}$ was $13.82 \%$ compared to 6.2 and $9.7 \%$ in the F. chinensis and $P$. trituberculatus systems, respectively.

\subsection{Low TL catches do not cause the system to collapse}

The system of increasing the yield of commercial invertebrate species by enhancing habitat and through release programs clearly approaches a level of mariculture, sometimes referred to as sea or marine ranching (Bell et al. 2006). In the Laizhou AR ecosystem, A. japonicus and $R$. venosa represent the most important fishery industries in terms of biomass (ca. 150 versus $116.5 \mathrm{t} \mathrm{km}^{-2}$ ) and fishery yield (ca. 32.81 versus $89.07 \mathrm{t} \mathrm{km}^{-2}$ ), respectively (Table 2). Fishing landings of Octopodidae, S. schlegelii, $H$. otakii, Gobiidae, C. japonica and Oratosquilla oratoria totaled $0.468 \mathrm{t} \mathrm{km}^{-2} \mathrm{yr}^{-1}$ in $S_{\mathrm{AR}+\mathrm{Re}}$, reaching $0.75 \%$ of total system production and $0.15 \%$ of total market value (1772.3 US\$ $\mathrm{yr}^{-1}$ ) (Table 2). The production of $R$. venosa was ca. $47.15 \%$ of total production and $5.32 \%$ of total market value (Table 2 ). The production of A. japonicus was ca. $52.1 \%$ of total production and $94.53 \%$ of total market value (Table 2).

In the Ecopath model, fishing activities can be assessed by looking at the mean trophic level of the catch (TLc) and the gross efficiency of the fishery (catch/PP) (Pauly \& Christensen 1995, Pauly et al. 1998). The TLc is an index of sustainability and reflects the strategy adopted by a fishery in terms of the targeted food web components. TLc was 2.484 in $S_{\mathrm{AR}+\mathrm{Re}}$ and 3.012 in $S_{\mathrm{AR}}$ compared to a value of 2.09 in the AR area of Li Island, China (Wu et al. 2012) and 2.27 in the natural rocky reefs of Galápagos, Chile (Okey et al. 2004). TLc values in Laizhou are close to the average global estimate for coastal and reef systems $($ TLC $=2.5)$ (Pauly \& Christensen 1995). The gross efficiency of the fishery can have high values in systems where fisheries harvest fish low in the food web, and in this study the estimated value was substantially higher than the mean global value of 0.0002 reported by Christensen et al. (2005).

Although A. japonicus and $R$. venosa are under intense fishing pressure due to considerable economic interests, low TL catches do not cause the system to collapse in the study area. The MTI analysis showed positive impacts of $R$. venosa on most groups except for oyster and sea cucumber. Sea cucumber had negative impacts on detritus, $R$. venosa and diving fishing. This was also supported by the keystone species analysis. After AR deployment, the major economic species $C$. japonica, $R$. venosa and sea cucumber ranked $3^{\text {rd }}, 11^{\text {th }}$ and $13^{\text {th }}$, respectively. These species exhibited few trophic cascade impacts on other functional groups and are thus mainly regarded as exploited species due to their large populations.

According to MTI analysis, diving fishing and crab pot fishing have negative impacts on target species and a small positive impact on groups at lower levels because of reduced predation pressure and competition when the stocks of predators and other major groups decline. Diving fishing showed negative effects on sea cucumber and $R$. venosa while it had a small positive effect on oyster. Crab pot fishing showed negative effects on $H$. otakii, S. schlegelii and Octopodidae, but positive effects on large crustaceans and demersal fishes. Compared to ARs, which were shown to only increase recreational fishing opportunities for reef fishes in several areas worldwide (Sutton \& Bushnell 2007, Mclean et al. 2015, Keller et al. 2016), artificial oyster reefs support the sustained commercial use of A. japonicus and $R$. venosa.

Ecosystem-based fisheries management (Prellezo \& Curtin 2015) is an environmental management paradigm that addresses complex socio-ecological problems. The goal of ecosystem-based fisheries management is to maintain an ecosystem in a healthy, 
productive and resilient condition. AR deployment as a technological means focuses on comprehensive, multi-dimensional, long-term ecosystem improvements in order to increase the health and maturity of ecosystems. Fisheries managers can use AR deployment to manage degrading nearshore marine ecosystems, help local fisheries communities to increase their income through mariculture, and exploit fisheries resources in a sustainable way. In this context, this study provides useful new insights on the effects of AR deployment on marine ecosystems.

\section{CONCLUSIONS}

This study provides a summary of the knowledge on ecosystem status before and after AR deployment, including trophic interactions, energy flows, keystone species, ecosystem properties and fishing impacts, through a steady-state trophic flow model (EwE 6.5). It is important to implement quantitative assessments of energy and matter flows in coastal AR ecosystems for a better understanding of the underlying ecological processes and to improve our ability to predict changes in ecosystem functions in response to environmental and anthropogenic impacts (Gaedke 1995). The following conclusions can be drawn from this study: (1) AR deployment contributes to the maturity of an improved ecosystem $;$ (2) the artificial oyster system is close to a natural reef ecosystem; (3) the enhancement and release of benthic organisms in AR areas benefit the ecosystem; and (4) low TL catches do not cause the system to collapse. Keystone species and MTI analyses helped explain short-term ecosystem changes (Mavuti et al. 1996) in this study. Future studies should focus on predictions of medium- and long-term ecosystem dynamics.

Acknowledgements. The authors thank Mr. T. Shi and the members of Blue Ocean Ltd. for their help with field sampling, and members of the CAS Key Laboratory of Marine Ecology and Environmental Sciences, the Institute of Oceanology and the Chinese Academy of Sciences for their constructive discussions and encouragement. This research was supported by the Taishan Industry Leader Talent Project, the Strategic Priority Research Program of the Chinese Academy of Sciences (Grant No. XDA11020703), the Qingdao Postdoctoral Applied Basic Research (Grant No. Y7KY02106N), the NSFC-Shandong Joint Fund for Marine Science Research Centers (Grant No.U1406403), the Key Research and Development Plan (major key technology) Project in Shandong (Grant No. 2016ZDJS06A02), the National Marine Public Welfare Research Project (Grant No. 201305043), the Postdoctoral International Exchange Program Introduction Project (Grant No. Y8KY02102L), the Laboratory for Marine Fisheries Science and Food Produc- tion Processes and the Qingdao National Laboratory for marine science and technology (2016LMFS-B08). This study was also financially supported by a Creative Team Project of the Laboratory for Marine Ecology and Environmental Science, Qingdao National Laboratory for Marine Science and Technology (No. LMEES-CTSP-2018-1). We thank International Science Editing (www.internationalscienceediting. com) for editing the manuscript.

\section{LITERATURE CITED}

Alongi DM, Trott LA, Pfitzner J (2008) Biogeochemistry of inter-reef sediments on the northern and central Great Barrier Reef. Coral Reefs 27:407-420

Baine M (2001) Artificial reefs: a review of their design, application, management and performance. Ocean Coast Manage 44:241-259

Baird D, Christian RR, Peterson CH, Johnson GA (2004) Consequences of hypoxia on estuarine ecosystem function: energy diversion from consumers to microbes. Ecol Appl 14:805-822

Bell JD, Bartley DM, Lorenzen K, Loneragan NR (2006) Restocking and stock enhancement of coastal fisheries: potential, problems and progress. Fish Res 80:1-8

Borsje BW, Wesenbeeck BKV, Dekker F, Paalvast P, Bouma TJ, Katwijk MMV (2011) How ecological engineering can serve in coastal protection. Ecol Eng 37:113-122

Bray RN, Miller AC, Geesey GG (1981) The fish connection: A trophic link between planktonic and rocky reef communities? Science 214:204-205

* Bruce T, Meirelles PM, Garcia G, Paranhos R, Rezende CE, Moura RLD (2012) Abrolhos Bank reef health evaluated by means of water quality, microbial diversity, benthic cover, and fish biomass data. PLOS ONE 7:e36687

Chen J (2004) Present status and prospects of sea cucumber industry in China. In: Lovatelli A, Conand C, Purcell S, Uthicke S, Hamel JF, Mercier A (eds) Advances in sea cucumber aquaculture and management. FAO Fisheries Technical Paper No. 463. FAO, Rome, p 25-38

Choo PS (2008) Population status, fisheries and trade of sea cucumbers in Asia. In: Toral-Granda V, Lovatelli A, Vasconcellos M (eds) Sea cucumbers: a global review of fisheries and trade. FAO Fisheries and Aquaculture Technical Paper No. 516. FAO, Rome, p 81-118

* Christensen V (1995) Ecosystem maturity - towards quantification. Ecol Modell 77:3-32

Christensen V, Walters CJ (2004) Ecopath with Ecosim: methods, capabilities, capabilities and limitations. Ecol Modell 172:109-139

Christensen V, Walters CJ, Pauly D (2005) Ecopath with Ecosim: a user's guide. Fisheries Center, University of British Columbia, Vancouver

Claudet J, Pelletier D (2004) Marine protected areas and artificial reefs: a review of the interactions between management and scientific studies. Aquat Living Resour 17: 129-138

Dillon KS, Peterson MS, May CA (2015) Functional equivalence of constructed and natural intertidal eastern oyster reef habitats in a northern Gulf of Mexico Estuary. Mar Ecol Prog Ser 528:187-203

F Falcão M, Santos MN, Vicente M, Monteiro CC (2007) Biogeochemical processes and nutrient cycling within an artificial reef off southern Portugal. Mar Environ Res 63: 429-444 
Freitas LELD, Feitosa CV, Araújo MED (2006) Mangrove oyster (Crassostrea rhizophorae) (Guilding, 1928) farming areas as artificial reefs for fish: a case study in the state of Ceará, Brazil. Braz J Oceanogr 54:31-39

Gaedke U (1995) A comparison of whole-community and ecosystem approaches (biomass size distributions, food web analysis, network analysis, simulation models) to study the structure, function and regulation of pelagic food webs. J Plankton Res 17:1273-1305

Golikov AN, Skarlato OA (1967) Molluscs of Posyet Bay (Japan Sea) and their ecology. Proc Zool Inst 42:5-155 (In Russian)

Grizzle RE, Greene JK, Luckenbach MW, Coen LD (2006) A new in situ method for measuring seston uptake by suspension-feeding bivalve molluscs. J Shellfish Res 25: 643-649

* Grosholz ED, Ruiz GM, Dean CA, Shirley KA, Maron JL, Connors PG (2000) The impacts of a nonindigenous marine predator in a California Bay. Ecology 81:1206-1224

Guan ML, Zheng T, You XY (2016) Ecological rehabilitation prediction of enhanced key-food-web offshore restoration technique by wall roughening. Ocean Coast Manage 128:1-9

Han Q, Keesing JK, Liu D (2016) A review of sea cucumber aquaculture, ranching, and stock enhancement in China. Rev Fish Sci 24:326-341

* Heymans JJ, Coll M, Link JS, Mackinson S, Steenbeek J, Walters C, Christensen V (2016) Best practice in Ecopath with Ecosim food-web models for ecosystem-based management. Ecol Modell 331:173-184

Iannibelli M, Musmarra D (2008) Effects of anti-trawling artificial reefs on fish assemblages: the case of Salerno Bay (Mediterranean Sea). Ital J Zool 75:385-394

Kakimoto H, Noda M, Tsumura K (2000) The functions of artificial reefs propagation. Proc Hokkaido Tokai Univ Sci Eng 13:19-24 (In Japanese with English Abstract)

Keller K, Steffe AS, Lowry M, Murphy JJ, Suthers IM (2016) Monitoring boat-based recreational fishing effort at a nearshore artificial reef with a shore-based camera. Fish Res 181:84-92

Kanglois TJ, Anderson MJ, Babcock RC (2006) Inconsistent effects of reefs on different size classes of macrofauna in adjacent sand habitats. J Exp Mar Biol Ecol 334:269-282

Lenihan HS, Peterson CH, Byers JE, Grabowski JH, Thayer GW, Colby DR (2001) Cascading of habitat degradation: oyster reefs invaded by refuges fishes escaping stress. Ecol Appl 11:764-782

Lin Q, Li Xs, Li Zy, Jin Xs (2013) Ecological carrying capacity of Chinese shrimp stock enhancement in Laizhou Bay of East China based on Ecopath model. Ying Yong Sheng Tai Xue Bao 24:1131-1140 (in Chinese with English Abstract)

* Lin Q, Wang J, Li ZY, Wu Q (2015) Assessment of ecosystem energy flow and carrying capacity of swimming crab enhancement in the Yellow River estuary and adjacent waters. Ying Yong Sheng Tai Xue Bao 26:3523-3531 (in Chinese with English Abstract)

Link JS (2010) Adding rigor to ecological network models by evaluating a set of pre-balance diagnostics: a plea for PREBAL. Ecol Modell 221:1580-1591

* Lira SMDA, Farrapeira CMR, Amaral FMD, Ramos CAC (2010) Sessile and sedentary macrofauna from the Pirapama shipwreck, Pernambuco, Brazil. Biota Neotrop 10: 155-165

Lowry M, Folpp H, Gregson M, Mckenzie R (2011) A com- parison of methods for estimating fish assemblages associated with estuarine artificial. Braz J Oceanogr 59: 119-131

Luckenbach MW, Coen LD, Ross PG Jr, Stephen JA (2005) Oyster reef habitat restoration: relationships between oyster abundance and community development based on two studies in Virginia and South Carolina. J Coast Res 40:64-78

* Mavuti K, Moreau J, Munyadrorero J, Plisnier PD (1996) Analysis of trophic relationships in two shallow equatorial lakes Lake Naivasha (Kenya) and Lake Ihema (Rwanda) using a multispecifies trophic model. Hydrobiologia 321:89-100

Mclean M, Roseman EF, Pritt JJ, Kennedy G, Manny BA (2015) Artificial reefs and reef restoration in the Laurentian Great Lakes. J Gt Lakes Res 41:1-8

* Moschella PS, Abbiati M, Åberg P, Airoldi L, Anderson JM, Bacchiocchi F (2005) Low-crested coastal defence structures as artificial habitats for marine life: using ecological criteria in design. Coast Eng 52:1053-1071

Moura A, Boaventura D, Cúrdia J, Santos MN, Monteiro CC (2006) Biomass production of early macrobenthic communities at the Faro/Ancão artificial reef (Portugal): effect of depth and reef layer. Bull Mar Sci 78:83-92

*Mustafa S, Saad S, Rahman RA (2003) Species studies in sea ranching: an overview and economic perspectives. Rev Fish Biol Fish 13:165-175

Myoung JG, Park YJ (2001) Monthly changes of fish fauna at experimental artificial reef in Tongyeong marine ranching area, Korea. Ocean Polar Res 23:311-313

* Odum EP (1969) The strategy of ecosystem development. Science 164:262-270

Odum EP (1971) Fundamentals of ecology. WB Saunders, Philadelphia, PA

Odum WE, Heald EJ (1975) The detritus-based food web of an estuarine mangrove community. In: Cronin LE (ed) Estuarine research, Vol 1. Academic Press, New York, NY, p 265-286

* Okey TA, Banks S, Born AF, Bustamante RH and others (2004) A trophic model of a Galapagos subtidal rocky reef for evaluating fisheries and conservation strategies. Ecol Modell 172:383-401

*Pauly D, Christensen V (1995) Primary production required to sustain global fisheries. Nature 374:255-257

*Pauly D, Christensen V, Dalsgaard J, Froese R, Torres F (1998) Fishing down marine food webs. Science 279: 860-863

* Pitcher TJ, Buchary EA, Hutton T (2002) Forecasting the benefits of no-take human-made reefs using spatial ecosystem simulation. ICES J Mar Sci 59:S17-S26

* Prellezo R, Curtin R (2015) Confronting the implementation of marine ecosystem-based management within the common fisheries policy reform. Ocean Coast Manage $117: 43-51$

* Rilov G, Benayahu Y (2000) Fish assemblage on natural versus vertical artificial reefs: the rehabilitation perspective. Mar Biol 136:931-942

* Rodney WS, Paynter KT (2006) Comparisons of macrofaunal assemblages on restored and non-restored oyster reefs in mesohaline regions of Chesapeake Bay in Maryland. J Exp Mar Biol Ecol 335:39-51

Ryther JH (1969) Photosynthesis and fish production in the sea. Science 166:72-76

* Sandu C, Iacob R, Nicolescu N (2003) Chlorophyll-a determination - a reliable method for phytoplankton biomass 
assessment. Acta Bot Hung 45:389-397

Santos MN, Lino PG, Pousãoferreira P, Monteiro CC (2006) Preliminary results of hatchery-reared seabreams released at artificial reefs off the Algarve coast (southern Portugal): a pilot study. Bull Mar Sci 78:177-184

Sayer MDJ, Wilding TA (2002) Planning, licensing, and stakeholder consultation in an artificial reef development: the Loch Linnhe reef, a case study. ICES J Mar Sci 59:S178-S185

Serrano A, Rodríguez-Cabello C, Sánchez F, Velasco F, Olaso I, PunzóA (2011) Effects of anti-trawling artificial reefs on ecological indicators of inner shelf fish and invertebrate communities in the Cantabrian Sea (southern Bay of Biscay). J Mar Biol Assoc UK 91:623-633

Sutton SG, Bushnell SL (2007) Socio-economic aspects of artificial reefs: considerations for the great barrier reef marine park. Ocean Coast Manage 50:829-846

Ulanowicz RE (1986) Growth and development: ecosystem phenomenology. Springer-Verlag, New York, NY

Vicente M, Falc OM, Santos MN, Caetano M, Serpa D, Vale C, Monteiro C (2008) Environmental assessment of two artificial reef systems off southern Portugal (Faro and Olhao): a question of location. Cont Shelf Res 28:839-847

Wang Q, Zhuang Z, Deng J, Ye Y (2006) Stock enhancement and translocation of the shrimp Penaeus chinensis in China. Fish Res 80:67-79

Watson JC (1993) The effects of sea otter (Enhydra lutris) foraging on shallow rocky communities off northwestern Vancouver Island, British Columbia. PhD thesis, University of California, Santa Cruz, CA

Wiebe PH (1988) Functional regression equations for zooplankton displacement volume, wet weight, dry weight, and carbon: a correction. Fish Bull 86:833-835

Wigan M (1998) The last of the hunter gathers: fisheries crisis at sea. Swall Hill Press, Manchester

Woo J, Kim D, Yoon HS, Na WB (2014) Characterizing Korean general artificial reefs by drag coefficients. Ocean Eng 82:105-114

Wu ZX, Zhang XM, Zhang L, Tong F, Liu HJ (2012) Structure and function of Lidao artificial reef ecosystem in Rongcheng of Shandong Province, East China: an evaluation based on Ecopath model. Ying Yong Sheng Tai Xue Bao 23:2878-2886 (In Chinese with English Abstract)

Wu ZX, Zhang XM, Lozano-Montes HM, Loneragan NR (2016) Trophic flows, kelp culture and fisheries in the marine ecosystem of an artificial reef zone in the Yellow Sea. Estuar Coast Shelf Sci 182:86-97

Xu M, Komatsu T (2016) Field measurement of drag force on Sargassum horneri (Turner) C. Agardh towed by a boat

Editorial responsibility: Gianluca Sará,

Palermo, Italy and estimation of its drag coefficient. Mer (Paris) 54: 77-86

Xu M, Sakamoto S, Komatsu T (2016) Attachment strength of the subtidal seaweed Sargassum horneri (Turner) C. Agardh varies among development stages and bottom depths. J Appl Phycol 28:3679-3687

* Xu M, Sasa S, Komatsu T (2018a) Sargassum horneri C. Agardh space capacity estimation reveals that thallus surface area varies with wet weight. PLOS ONE 13: e0199103

Xu M, Sasa S, Otaki T, Hu FX, Tokai T, Komatsu T (2018b) Changes in drag forces on small Sargassum horneri (Turner) C. Agardh individuals with and without vesicles revealed by a water tunnel experiment. Aquat Bot 144: 61-64

Xu Q, Zhang L, Zhang T, Zhang X, Yang H (2017) Functional groupings and food web of an artificial reef used for sea cucumber aquaculture in northern China. J Sea Res 119:1-7

Xu S, Chen Z, Li S, He P (2011) Modeling trophic structure and energy flows in a coastal artificial ecosystem using mass-balance Ecopath model. Estuaries Coasts 34: 351-363

Xu Z, Chen Y, Tian T, Liu YH, Ying ZQ, Liu HC (2016) Structure and function of an artificial reef ecosystem in Zhangzi Island based on Ecopath model. Dalian Haiyang Daxue Xuebao 31:85-94

Yang HS (2016) Construction of marine ranching in China: reviews and prospects. Shuichan Xuebao 40:1133-1140 (in Chinese with English Abstract)

*Yuan XT, Yang HS, Wang L, Yi Z, Gabr HR (2009) Bioenergetic responses of sub-adult sea cucumber Apostichopus japonicus (Selenka) (Echinodermata: Holothuroidea) to temperature with special discussion regarding its southernmost distribution limit in China. J Therm Biol 34:315-319

Zhang B, Li ZY, Jin XS (2012) Functional groups of fish assemblages and their major species in the Bohai Sea. Shuichan Xuebao 36:64-72 (in Chinese with English Abstract)

Zhang L, Yang H, Xu Q, Xing K, Zhao P, Lin C (2011) A new system for the culture and stock enhancement of sea cucumber, Apostichopus japonicus (Selenka) in cofferdams. Aquacult Res 42:1431-1439

Zhang S, Sun MC, Chen Y (2008) The attractive effects of different structural artificial reef models on juvenile Schlegel's rockfish Sebastes schlegeli and fat greenling Hexagrammos otakii. J Dalian Fish Univ 1:13-19 (in Chinese with English Abstract)

Submitted: April 25, 2018; Accepted: September 5, 2018 Proofs received from author(s): March 7, 2019 